WORKING PAPER - NO. 2020-133

\title{
COVID-19 Shifted Patent Applications toward Technologies that Support Working from Home
}

Nicholas Bloom, Steven J. Davis, and Yulia Zhestkova

JANUARY 2021

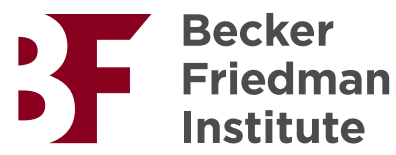




\title{
COVID-19 Shifted Patent Applications toward Technologies that Support Working from Home
}

\author{
Nicholas Bloom, ${ }^{1}$ Steven J. Davis ${ }^{2}$ and Zulia Zhestkova ${ }^{3}$
}

8 January 2021

\begin{abstract}
We examine the text content of U.S. patent applications, identifying those that advance technologies in support of video conferencing, telecommuting, remote interactivity, and working from home (collectively, WFH). The share of new patent applications that advance WFH technologies more than doubles from January to September of 2020, greatly surpassing its previous peak, and following an upward trajectory since the onset of the pandemic. This evidence suggests that (re-)directed technical change in reaction to COVID-19 will raise the quality and efficiency of remote work, thereby reinforcing a shift to working from home even after the pandemic ends.
\end{abstract}

Contacts: nbloom@stanford.edu, Steven.Davis@ chicagobooth.edu,yzhestkova@uchicago.edu,

JEL Nos.: O3, J21

Keywords: directed technical change, patents, COVID-19, coronavirus, working from home, remote interactivity, text analysis

Acknowledgements: We thank the University of Chicago Booth School of Business for financial support.

\footnotetext{
${ }^{1}$ Stanford University

${ }^{2}$ University of Chicago Booth School of Business and Hoover Institution

${ }^{3}$ University of Chicago
} 
COVID-19 triggered a massive shift to working from home. In the spring of 2020, American workers supplied roughly half of paid labor services from home. ${ }^{4}$ According to survey evidence in Barrero et al. (2020), 23 percent of all full work days will be supplied from home after the pandemic ends, as compared to just 5 percent in 2017-18. Stock prices also reflect the shift to working from home. For example, Papanikolaou and Schmidt (2020) report daily equity returns in 2020 for firms sorted by share of employees able to work remotely. From 14 February 2020 to 15 June, the cumulative return differential between the top and bottom quartiles is 19.4 percentage points, with most of the differential emerging by mid-March. Similarly, Pagano et al. (2020) find much higher returns in the wake of COVID-19 at "resilient" firms, as measured by the ability of their employees to perform jobs at home and without interactions in physical proximity.

These observations prompt us to ask whether COVID-19 has also shifted the direction of innovation toward technologies that support video conferencing, telecommuting, remote interactivity, and working from home (collectively, WFH). The economic reasoning is simple: When remote work becomes a bigger share of all work, the incentives to advance technologies that support WFH become stronger. Likewise, Acemoglu (1998) stresses that a high proportion of skilled workers in the labor force implies a large market size for skill-complementary technologies, creating incentives for skill-biased technical change. Motivated by this type of reasoning, we assess how forcefully the direction of technical change responds to a large, sudden, surprise shift in working arrangements.

Specifically, we use human-guided automated readings of U.S. patent applications, identifying the ones that advance WFH technologies. We start with the raw XML files of new

\footnotetext{
${ }^{4}$ See Barrero et al. (forthcoming), Bick et al. (2020), Brynjolfsson et al. (2020), and Ozimek, 2020.
} 
patent applications, which are published by the United States Patent and Trademark Office (USPTO) every Thursday. These files include the patent application date (filing date), publication date, application ID, inventor name, assignee (entity that owns the patent), patent class, title, and full text of the invention description. We examine the content of the invention descriptions to identify patent applications that advance WFH technologies. Our analysis sample contains all patent applications published from 7 January 2010 through 24 December 2020, which covers filings from 1 January 2010 to 11 September 2020. There are about 3.6 million patent applications in our dataset, 20,907 of which pertain to WFH technologies according to our classification algorithm described below.

As a first step, we construct a dictionary of terms that pertain to WFH technologies. To do so, we manually reviewed twenty articles about "working from home" "working from home technologies," "remote work tools" and the like drawn from online encyclopedias, newspapers, tech-oriented media, and popular blog posts. Based on our review, we created our dictionary of WFH terms: telecommuting, telework, teleworking, working from home, mobile work, remote work, flexible workplace, work from home, mobile working, remote working, work remotely, working remotely, remote workplace, telecommuter, teleworker, home-sourced worker, home-sourced employee, work-at-home, work at home, telecommuting specialist, nomadic worker, nomadic employee, work-from-home, work-from-anywhere, video conference, video conferencing, virtual office, distance work, flexible work, virtual work, virtual office, virtual employee, home office, home-based office, home-based work, work from anywhere, working from anywhere, work-from-anywhere, digital workplace, video chat, video call, teleconference, teleconferencing, working from a remote location, work from a remote location. 
Second, we execute computer-automated readings of the patent application texts that summarize the invention and describe its potential applications. If the text contains one or more terms in the dictionary above, we regard the patent application as one that advances WFH technologies. Similar results obtain when requiring the text to contain two or dictionary terms.

Sample titles (assignee, filing date) of patent applications selected by our WFH classification include "Method and System for Elevating a Phone Call into a Video Conferencing Session” (Zoom Video Communications, Inc., 20 March 2020), “Optimizing Video Conferencing Using Contextual Information" (Facebook, Inc., 30 April 2020), "Video Conference System, Video Conference Apparatus, and Video Conference Method" (Optoma Corporation, 5 May 2020)," "Speech Recognition and Summarization" (Google LLC, 18 May 2020), "Defining Content of Interest for Video Conference Endpoints with Multiple Pieces of Content" (Cisco Technology, Inc., 2 July 2020), and "Sales Management and Video Chat System and Method for a Salesperson Mobile Device and a Remote Visitor Web Browser" (Dealer Inside, Inc., 7 July 2020).

Before turning to our main results, we note there are long and variable lags from the filing of new patent applications until publication by the USPTO. ${ }^{5}$ That means our analysis sample misses a fraction of recent patent filings, and that fraction becomes larger near the end of our sample. Figure 1 shows the distribution of these lags for all published patent applications that

\footnotetext{
${ }^{5}$ Once the USPTO regards a patent application filing as complete, which can itself be a lengthy process, the application is assigned for examination. The examination process can also be lengthy. The publication of approved patent applications takes about fourteen weeks. The USPTO has various programs and initiatives to assist in the patent application process, some of which involve additional fees for an expedited process. For more information, see https://www.uspto.gov/web/offices/pac/mpep/s1120.html, https://www.uspto.gov/patentsgetting-started/patent-process-overview\#step6, and https://www.uspto.gov/patent/initiatives/uspto-patent-application-initiatives-timeline.
} 
were first filed from 1 January 2010 to 24 December 2018. The mean lag from filing to publication is 12.9 months for all patent applications and 11.5 months for those that support WFH technologies. The similarity of the lag structures suggests that the reported percentage of filings accounted for by patent applications that support WFH technologies is unlikely to be much distorted by publication lags, even near the end of our sample. ${ }^{6}$

[Figure 1 here]

Figure 2 reports the percentage of newly filed patent applications that support WFH technologies at a monthly frequency from January 2010 through September 2020. We compute this percentage as 100 times the ratio of (a) patent application filings in the month that support WFH technologies to (b) all patent application filings in the month. Interestingly, the WFH share of new patent applications rises from 0.53 percent in January 2020 to 0.73 percent in February, before the World Health Organization declared the novel coronavirus outbreak a global pandemic (Muccari et al., 2020). China reported the first death from COVID-19 in early January and imposed a lockdown in Wuhan on 23 January. By the end of January, the virus had spread to many other countries, including the United States. Figure 2 suggests that these developments had already - by February - triggered the beginnings of a shift in new patent applications toward technologies that support WFH.

[Figure 2 here]

By March, COVID-19 cases and deaths had exploded in many localities and countries around the world. Government-mandated lockdowns and voluntary social distancing responses led to an extraordinary collapse in economic activity. By April and May, half of paid work in the

\footnotetext{
${ }^{6}$ We are working on methods to adjust for the variable lags between the filing and publication of new patent applications, so that we can estimate recent flow levels as well as shares.
} 
United States was performed by persons working from home. As Figure 2 shows, the WFH percentage of new patent applications continued to rise after February. In September 2020, the WFH share of new patent applications reaches 1.16 percent, more than double its January value and greatly surpassing any month before the pandemic struck. Thus, we find clear evidence that COVID-19 has shifted the direction of innovation toward technologies that support WFH.

Other evidence also points to strong commercial incentives to acquire existing WFH technologies in the wake of the COVID-19 pandemic. For example, Verizon announced on 16 April 2020 that it would acquire BlueJeans, a video conferencing firm, for about $\$ 500$ million (Krause, 2020). Zoom announced on 7 May that it would acquire Keybase, an identity management firm (O'Flaherty, 2020). Adobe announced on 9 November that it would acquire Workfront, a leading work management platform for marketers, for $\$ 1.5$ billion (Bloomberg, 2020). And Salesforce announced on 1 December that it had agreed to acquire Slack, a workplace software company, for $\$ 27.7$ billion (Griffith and Hirsh, 2020).

It will be interesting to track the flow of new WFH patent applications in the coming months and years. One possibility is that the recent surge mainly reflects a pipeline acceleration effect, whereby firms with nearly-completed WFH innovations rush to patent them in response to the pandemic-induced shift to remote work. In that case, the WFH share might return to its prepandemic baseline in 2021 - or even temporarily fall below its baseline. A second view is that Figure 2 shows the beginnings of a persistent rise in the flow of new patents that advance WFH technologies. The ongoing upward trajectory in the WFH share since the pandemic struck favors this second view.

Under the second view, the directional shift in innovation will drive continuing improvements in WFH technologies and the tools and platforms that support WFH activity even 
after the COVID-19 pandemic comes under control. By improving the quality and productivity of remote work activity, a more rapid advance of WFH technologies will reinforce the shift to working from home even after the pandemic ends.

Barrero, Bloom and Davis (2020) provide evidence of several other mechanisms that will drive a persistent shift to working from home in the wake of the COVID-19 pandemic. These other mechanisms include better-than-expected experiences in working from home since the pandemic struck, investments in physical and human capital that enable and support working from home, a greatly diminished stigma associated with working from home, and an expressed desire by many people to avoid public transport and crowded facilities even after the pandemic ends due to lingering fears of infection risk.

\section{References}

Acemoglu, Daron, 1998. "Why Do New Technologies Complement Skills? Directed Technical Change and Wage Inequality," Quarterly Journal of Economics, 113, no. 4, 1055-1089.

Barrero, Jose Maria, Nick Bloom, and Steven J. Davis, forthcoming. "COVID-19 Is Also a Reallocation Shock.” Brookings Papers on Economic Activity.

Barrero, Jose Maria, Nick Bloom, and Steven J. Davis, 2020. "Why Working from Home Will Stick.” Working Paper, December 2020.

Barrero, Jose Maria, Nick Bloom, and Steven J. Davis, 2021. “COVID-19 Is a Persistent Reallocation Shock." Paper presented at the American Economic Association meetings.

Bick, Alexander, Adam Blandin and Karel Mertens, 2020. "Work from Home after the COVID19 Outbreak," Federal Reserve Bank of Dallas Working Paper 2017, June.

Bloomberg, 2020. "Adobe to Acquire Workfront," 9 November. 
Brynjolfsson, Eric, John J. Horton, Adam Ozimek, Daniel Rock, Garima Sharma and Hong-Yi TuYe, 2020. “COVID-19 and Remote Work: An Early Look at U.S. Data,” NBER Working Paper 27344.

Griffith, Erin and Lauren Hirsh, 2020. “Salesforce to Acquire Slack for \$27.7 Billion,” New York Times, 1 December.

Krouse, Sarah, 2020. "Verizon Buys Zoom Conferencing Rival BlueJeans," Wall Street Journal, 16 April.

Muccari R., Chow D. and Murphy J., 2020. "Coronavirus timeline: Tracking the critical moments of COVID-19," NBC News, updated 8 July.

O’Flaherty, Kate, 2020. “Zoom Buys Keybase in Bold New Security Move,” Forbes, 7 May.

Ozimek, Adam, 2020. “The Future of Remote Work,” SSRN Working Paper.

Pagano, Marco, Christian Wagner and Joseph Zechner, 2020. "Disaster Resilience and Asset Prices," COVID Economics: Vetted and Real-Time Papers, Issue 21, 22 May.

Papanikolaou, Dimitris and Lawrence D.W. Schmidt, 2020. "Working Remotely and the SupplySide Impact of COVID-19," NBER Working Paper No. 27330. 
Figure 1. Lags in the Filing of Patent Applications to their Publication by the USPTO

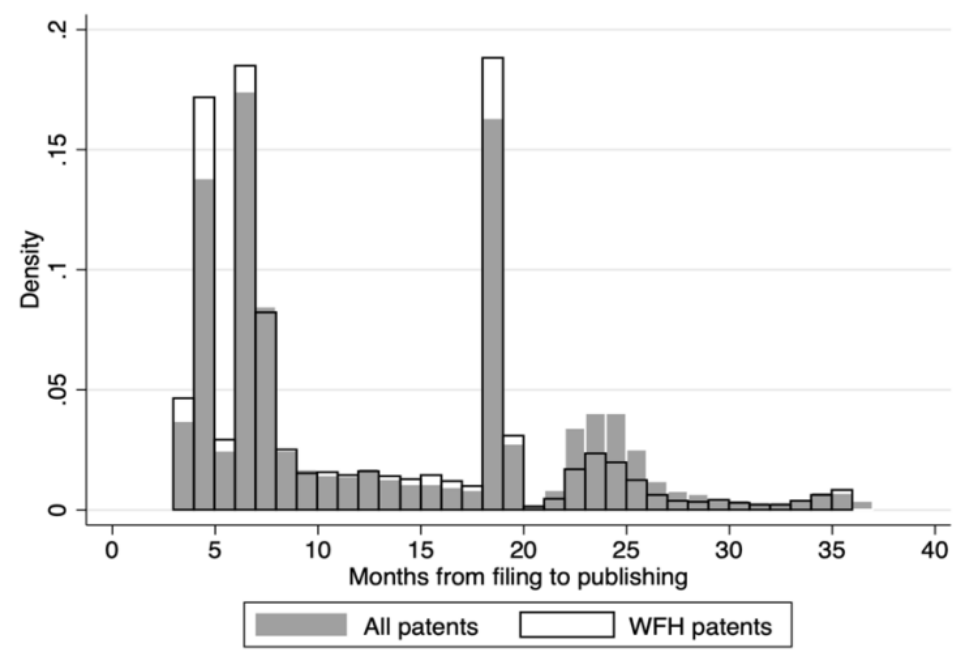

Source: Authors' analysis of XML files of published patent applications that were filed with the United States Patent and Trademark Office from 1 January 2010 through 24 December 2018.

Figure 2. Percent of New Patent Applications that Support Work-from-Home Technologies, January 2010 to September 2020

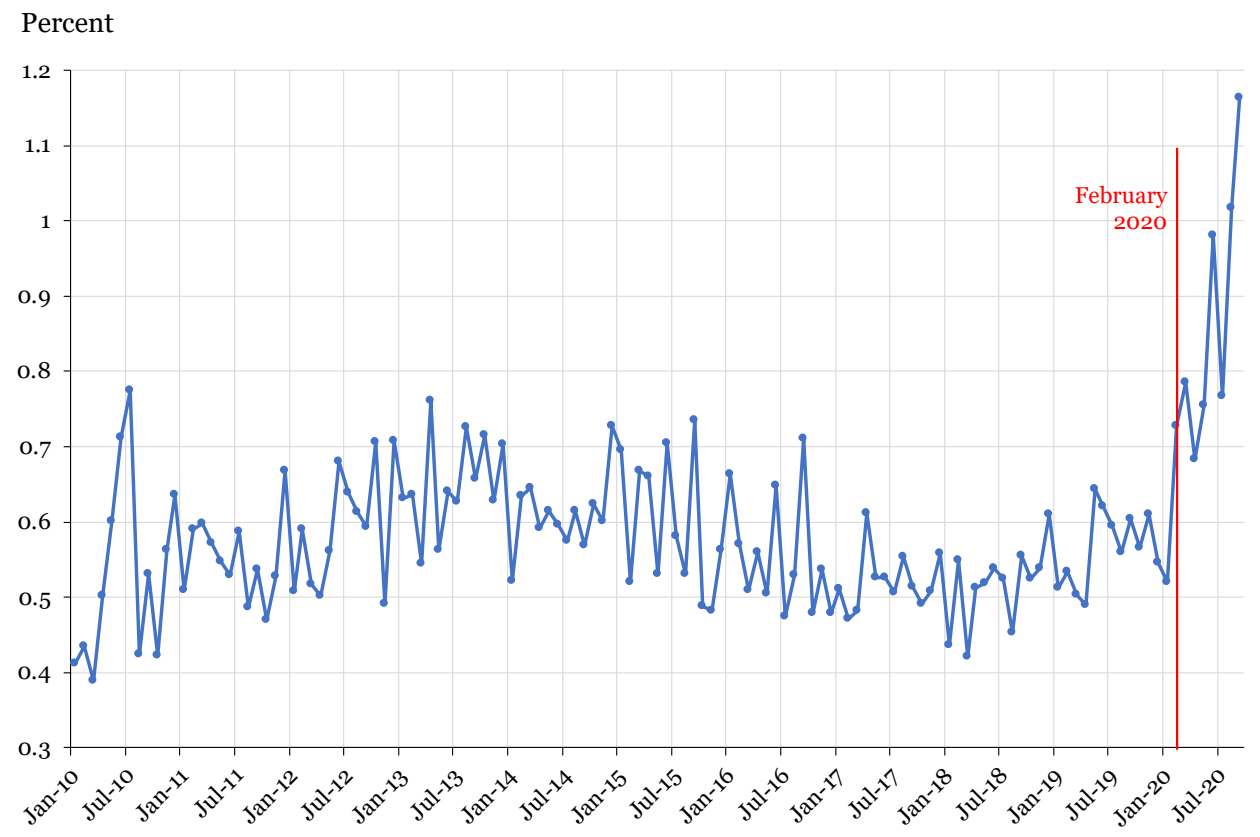

Source: Authors' analysis of XML files of patent applications published by the USPTO from 7 January 2010 through 24 December 2020, covering filings through 11 September 2020.

Note: The chart reports the percentage of patent application filings through 11 September 2020 that support WFH technologies. We calculate this percentage using our automated classification of invention descriptions in patent applications published through 24 December 2020. 